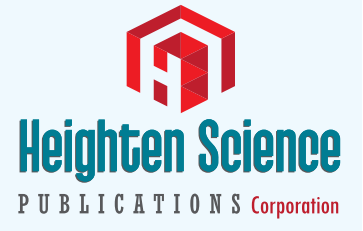

ISSN

2639-9911

\title{
Effect of spiritual health (Sound Heart) on the other dimensions of health at different levels of prevention
}

\author{
Minoo Asadzandi ${ }^{1-4 *}$ \\ ${ }^{1}$ Assistant Professor, Department of Anesthesiology, Nursing Faculty, Baqiyatallah University of \\ Medical Sciences, Tehran, Iran \\ ${ }^{2}$ Reaserch Fellow of Religion and Medicine Research Center, Baqiyatallah University of Medical \\ Sciences, Tehran, Iran \\ ${ }^{3}$ Faculty Member of Spiritual Health of the Academy of Medical Sciences in Iran, Iran \\ ${ }^{4}$ Founding Member of Spiritual Health Research Center, Qom University of Medical Sciences, \\ Qom, Iran
}

\begin{abstract}
*Address for Correspondence: Minoo Asadzand Founding Member of Spiritual Health Research Center, Qom University of Medical Sciences, Qom, Sheikh Baha'i Street Southern, Molla Sadra Ave. Vanak Square, P.O. Box: 19575-174, Tehran, Iran, Tel: 98+- 9123769064;

Email: zandi498@yahoo.com

Submitted: 05 September 2018

Approved: 20 September 2018

Published: 21 September 2018

Copyright: ( ) 2018 Asadzandi M. This is an open access article distributed under the Creative Commons Attribution License, which permits unrestricted use, distribution, and reproduction in any medium, provided the original work is properly cited
\end{abstract}

Keywords: Spiritual health; Sound heart; Levels of prevention; Dimensions of health

Check for updates

\section{Abstract}

Introduction and goal: From the perspective of Islam, spiritual health means having a Sound Heart (a calm, confident and optimistic soul, with hope for God's mercy, satisfaction with destiny and vitality). The way to achieve spiritual health is strengthening the faith and taking good deeds based on religious spirituality. This study was conducted with the aim of determining the impact of spiritual health (Sound Heart) on the other aspects of health at different levels of prevention.

Methods: In nine phases of research in 16 years, after designing and validating the "Sound Heart Model". The spiritual problems of patients and healthy clients were determined. Spiritual care guidelines and the spiritual counseling model in patients and healthy clients were designed. Then "Parent's Spiritual Empowerment Program", "inter-professional spiritual health care training program" was extracted. Based on the findings of the previous steps, the effect of spiritual health on other aspects of health at different levels of prevention was extracted.

Findings: Belief in God and divine love creates spiritual health (Sound heart) with wisdom, chastity, courage, justice, dignity, kindness, and sincerity in action. Faith prevents neglecting from the God's remembrance and its consequences such as: unhealthy lifestyle, risky behaviors, destructive excitements, psychosocial diseases in clients and eliminates the fear, anxiety, sadness and disappointment in patients. Spiritual health causes living in the present time with patience and grace of God, creates hope, optimism for the future, courage to face life crises. By creating mental health, it improves the psycho-neuron-immunologic function and improves physical health.

Conclusion: Considering the great impact of spiritual health on the other aspects of health at all levels of prevention, it is imperative that students and health care staff, by referring to these concepts, carry out spiritual care/counseling.

\section{Introduction}

Today, the influence of genetic and environmental factors, immune function, unhealthy habits and lifestyle, risky behaviors, destructive excitements on the occurrence of various types of diseases has been highlighted [1]. The role and impact of spiritual health is considered by the nursing theorists as a factor that gives patients a sense of tranquility, strength and vitality [2]. Its effect has been identified in the treatment of illness and the health promotion [3].

From the perspective of Islam, spiritual health means having a Sound Heart (a calm, confident and optimistic soul, with hope for God's mercy, satisfaction with destiny and vitality) which is achieved with religious spirituality by strengthening faith and good deeds [4]. The effect of spiritual health as the fourth dimension of health on the bio-psycho-social health, is considered by researchers around the world [5]. 
Also, its effect at different levels of prevention [6] in preventing the emergence of "risk factors of disease "and the onset of illness [7] for timely and appropriate treatment and prevention of complications of disease, and for patient's rehabilitation and returning to daily life activities [8] was investigated.

But the question is based on the spirituality of the Abrahamic religions: How can spiritual health by belief in God and divine love can affect different levels of prevention? And prevents of bio- psycho- social disease? Why is spiritual well-being necessary, in active young people, in healthy individuals with high physical ability, in different stages of development (for children and teens, pregnant women, for the elderly) [9]? And in different classes of society for fathers, mothers, children [10], teachers and students and professors and staff of the health system [11]? How does spiritual health help the acute, chronic, disabled or dying patients [2]?

Why do many scholars believe that: The uncertainty of life events and the crisis of illness create spiritual needs that generate spiritual responses and provide opportunities for spiritual care [13] and basically, spiritual care as an essential component of holistic care involves understanding the spiritual beliefs of the client / patient, and recognizing his spiritual needs [14]? So the members of the health team should increase their knowledge about spirituality and the influence of spiritual beliefs on lifestyle, response to the disease, choice of care and treatment1. They should integrate spirituality in health services [15]. Why it should be noted that ignoring each dimension of a patient has significant consequences for his or her life, causes the patient to feel incomplete and interfere with the recovery process [16]? This study was conducted with the aim of determining the impact of spiritual health (Sound Heart) on the other aspects of health at different levels of prevention.

\section{Methods}

This study is the result of the nine phases of the investigation taken over one and half decades:

1- Vienna's psychotherapy theories, systemic theory, homeostasis and quantum theory, rules of physics, humans' needs, characteristics of a perfect human in psychology as assumptions of nursing care models, and over 35 nursing care models, were studied $[5,17]$.

2- Seven universal care models were analyzed based on total ratio analysis that is comparable to the perceptual analysis and communication analysis of Carly in nursing [18].

3- Meta-paradigmatic concepts of the model were defined. The concept of soul was derived from the paradigm of Abrahamic religions, and the concept of sound hearth was derived from Quran and hadiths based on the method of adopting concepts [19].

4- The spiritual care model of sound heart was developed, by using grounded theory method [20].

5- To examine the concept of sound heart in real situations and define experimental parameters and themes of that concept, propositions were extracted through interviewing with patients and their family, clinical observations over the professional life of the researcher, field notes, interviewing with clinical nurses, nursing professors, and clinical psychologists. The client and patients' spiritual reactions to diseases was developed by using the extracted propositions [1].

6- Religious evidence-based guidelines of Sound Heart pastoral care model for hospitalized patients and clients were designed and validated $[9,12,21]$. 
7- Descriptive theory was developed and examined [22-28] health education models and motivation theories were content analyzed and used in clinical research: including health belief in diabetic patients [29], health promotion in soldiers with high-risk behaviors [30], precede-precede model for primary sleep disorder of military nurses [31,32]. After focus group meetings with professors of: health education, nursing, and psychology, all relevant concepts for implementing the training model were adopted and then organized as a relevant whole within a model. The spiritual care consulting model was developed by using the threestep theory synthesis of Walker and Avant [33].

8- Considering the constructs of spiritual care consulting model of Sound Heart, after adopting appropriate themes and clinically use of prominent models, "Parent's Spiritual Empowerment Program" was extracted from previous research findings and was accredited by ten professors of the Academy of Medical Sciences, pediatric oncology specialist, nursing and health education professors in three rounds of Delphi [34].

9- Based on the findings of the previous steps, inter professional spiritual healthcare education program for Students of Health Sciences was developed [35].

Accuracy and reliability of the qualitative data analysis: The following items were performed to determine accuracy and reliability of the qualitative data analysis: 1-Long-term engagement and continuous observation 2-Integration 3-Peer review 4-Search for contrary evidence 5- Acceptability of the researcher 6- Determination 7Review by participants [36].

\section{Results}

At various levels of prevention, spiritual health leads religious followers: (Figures 1,2).

- To go away from risk factors of disease (high-risk sexual behaviors, drug

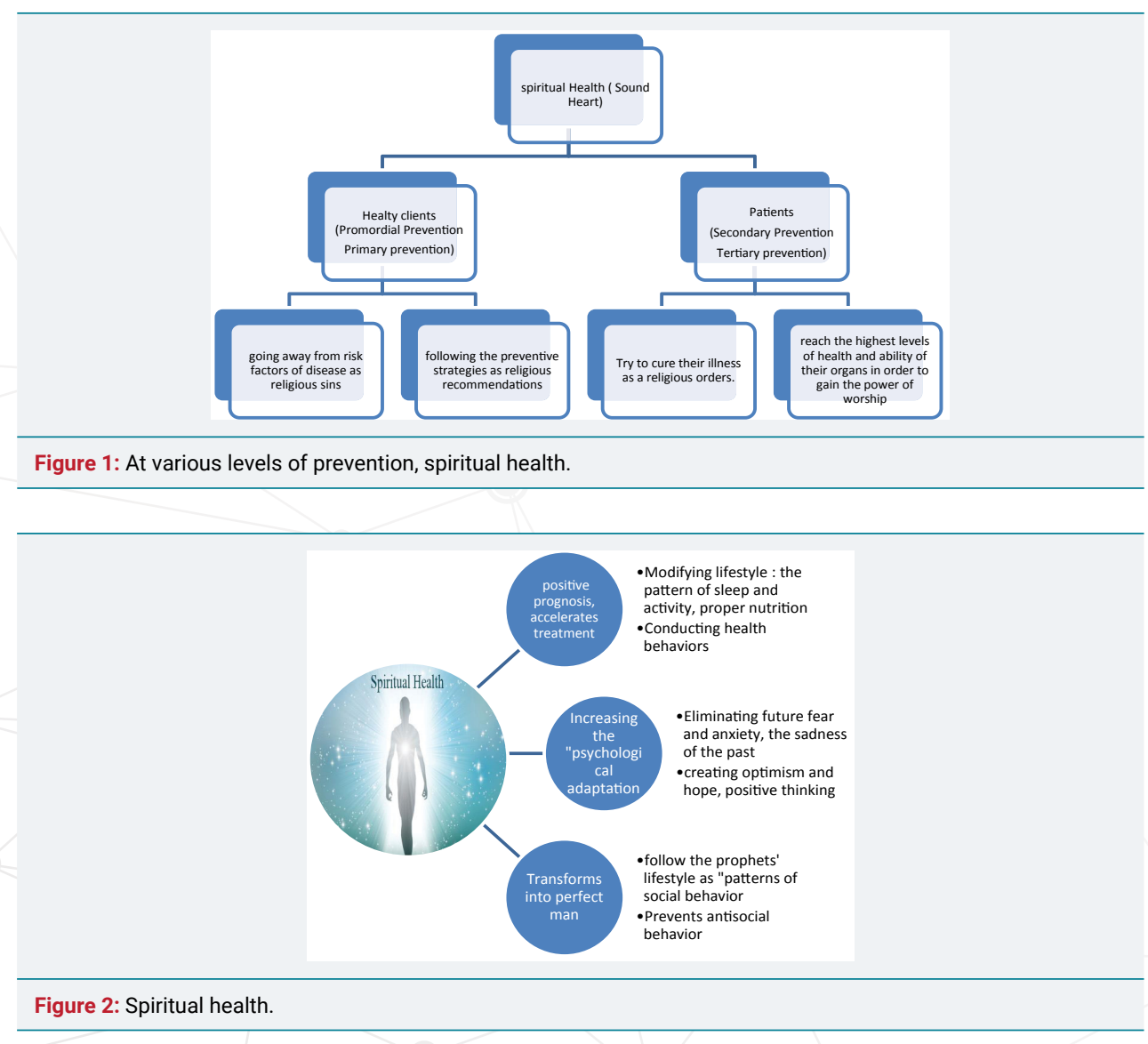


addiction, alcoholism, smoking, etc.) as religious sins [37]. Because in Islamic jurisprudential rules, anything that is harmful is forbidden.

- To follow the preventive strategies as religious recommendations [38]. 264 Quran verses deals with important health topics. Such as: eating healthy foods and avoiding wine, carrion, blood and pork as well as sexual hygiene, observing personal and environmental health, using non-polluted water, etc.) [39].

- To use prayer along with medical treatments [40]. Try to cure their illness as a religious orders. Accept death as a stage of life .Do not commit suicide even with the most severe diseases [41].

- To reach the highest levels of health and ability of their organs in order to gain the power of worship and to rehabilitate themselves (Surah Baqara / I247) [42]. Imam Musa Kazem (peace be upon him) said: "O God! I ask you health and wellbeing, and I ask you for good health [43].

Spiritual health (having a sound heart) protects humans against various diseases in different dimensions of health, Including:

1- Physical illnesses by:

Creating peace and calm

Managing emotions such as: fear, anxiety, anger...

Modifying lifestyle : the pattern of sleep and activity, proper nutrition and the avoidance of any addiction

Conducting health behaviors

Spiritual health in patients reduces the duration of the disease, create positive prognosis, and accelerates treatment and re-empowerment [44].

2- Mental illnesses and types of neuroses by:

Providing the opportunity to live in the present.

Eliminating future fear and anxiety, the sadness of the past.

Reducing stress by creating optimism and hope, positive thinking along with a sense of satisfaction from life's past.

Increasing the potential of "psychological adaptation "[45].

3- Social Diseases by:

Spiritual health transforms "followers of the Abrahamic religions" into social reformers because they follow the prophets' lifestyle as "patterns of social behavior"

Prevents antisocial behavior.

Spiritual health, with wisdom, creates the possibility of chastity and courage to combat moral corruption.

Brings the person to justice, kindness and dignity

Transforms him into a perfect man [30].

\section{Discussion}

In all Abrahamic religions, there is the belief in the existence of the soul from 
the unseen universe (Surah Al-Baghra/2) as the most important aspect of human existence which has eternal life. The soul as the commander of the body gives man the opportunity to communicate with God [46]. Relationship with God creates spiritual health (Sound heart) with wisdom, chastity, courage, justice, dignity, kindness, and sincerity in action [47].

The owners of Sound heart believe that God created his servants with much affection and gave them the best things (Surah Al-Baghra/30). God created the world from heaven and earth in six days and arranges the creation of the universe in a good form (Surah Younes / 3). God has endless power, whose powerful hands are not tied to the rules of the creation world (Surah Ma'eda / 64) and at any moment he is doing a new creation and doing a miracle (Surah al-Rahman / 29) [48]. These beliefs give them, true love, hope and optimism, peace and security [15].

Believe in the God who is alive and eternal without forgetting and sleeping (Surah al-Baqara / 255), and does not abandon his servants, gives confidence to believers [49]. Belief in God saves believers, from fear, future anxiety and sadness about the past [45]. Having Sound heart causes the proper connection of man with himself and people and the world of nature in the light of faith in God. Religious spirituality gives human thoughts, feelings, behaviors and intentions in a divine direction (Surah al-Anam / 162) [50].

Also, Islam identifies the Prophet as a role-model for individual and social life, for those who hope in God and the Last Day, and remember God (Surah al-Hazab / 21) [51]. They act according to their Prophet's lifestyle and try to improve their environmental conditions [52].

Believe that: my God is the one who created me and leads me, and gives me food and drinks, and when I get sick, he heals me (Surah al-Sha'ra / 78-80) in the course of illness, gives to the owner of Sound heart, optimism to God. They considers all the events of life under his authority and his permission, and sees in the heart of each sheer a great benefit (Surah al-Baqara / 216). The suffering of the illness will be holy to him, because he considers the world under the control of the Most Merciful God [53].

But any disruption of communication with God leads to disturbance in other communications and creates spiritual distress which occurs in the form of high-risk verbal or non-verbal behaviors, unhealthy life style, destructive emotions (jealousy, hatred and revenge, aggression, etc.) [1,54].

\section{Conclusion}

The owners of Sound heart reach spiritual health by gaining wisdom, chastity, courage, justice, friendship and intercession. So that they find a meaning in critical situations. Can bear their suffering. Spiritual health is essential, for health personnel, patients, families and healthy clients.

\section{Acknowledgement}

Sincere thanks and appreciation are to the professors who collaborated in conducting this study.

\section{References}

1. Asadzandi M. Clients and Patients' Spiritual Nursing Diagnosis of the Sound Heart Model. Journal of Community Medicine \& Health Education. 2017; 7: 2-6. Ref.: https://goo.gl/o52mys

2. Azizi F. Encyclopedia of Spiritual Health. Tehran: Publications of the Academy of Medical Sciences of the Islamic Republic of Iran. 2018.

3. McSherry W, Draper $P$. The debates emerging in the literature surrounding the concept of spirituality as applied to nursing, J Adv Nurs. 2002; 27: 683-691. Ref.: https://goo.gl/Nx5bZ6

4. Asadzandi M. Access to the Sound Heart identifies the concept of spiritual health. Journal of Medical Jurisprudence. 2014; 6: 143-173. 
5. Asadzandi M. Analysis of nursing concepts and theories with introduce Sound Heart model. Tehran: Publication Hydrae. 2014; 250-256.

6. Azizi F. Explanation of the spiritual health cares at different levels of prevention. Med History J. 2017; 8: 165-183. Ref.: https://goo.gl/57Fk8f

7. Asadzandi M. Spiritual health consulting model for health promotion in clients. Health, Spirituality and Medical Ethics Journal. 2018; 5: 9-15. Ref.: https://goo.gl/NiX96E

8. Koenig HG. Spirituality in patient care: why, how, when and what. 2th ed. Philadelphia: Templeton Foundation Press. 2007.

9. Asadzandi M, Eskandari AR. Religious Evidence-Based Spiritual Self-Care Guidelines in Anger Management. J Health Edu Res Dev. 2018; 6: 255. Ref.: https://goo.gl/v5G8tL

10. Asadzandi M. a guide to spiritual care for the family of patients. Tehran; Resaneh- takhassosi publication. Iran. 2018.

11. Asadzandi M. Spiritual Health Guide for Students and Health System Workers. Tehran; Resanehtakhassosi publication. Iran. 2018.

12. Asadzandi M, Eskandari A, Khademolhosseini SK, Ebadi A. Designing and Validation Islamic Evidence-Based Spiritual Care Guidelines of Sound Heart Model in the Dying Patients. Iran journal Critical Care Nursing. 2017; 10: 1-6. Ref.: https://goo.gl/VkQWk1

13. Cavendish R, Konecny L, Mitzeliotis C, Russo D, Luise B, et al. Spiritual care activities of nursing, using Nursing Intervention Classification (NIC) labels. Int J Nurs Terminol Classif. 2003; 14: 113-124. Ref.: https://goo.gl/kL99xQ

14. Asadzandi M. Spiritual care. Tehran; Resaneh- takhassosi publication. Iran. 2016.

15. Asadzandi M. Spiritual Care Guide for Patients: Tehran: Publications of the Academy of Medical Sciences of the Islamic Republic of Iran. 2017.

16. Coruh B, Ayele H, Pugh M, Mulligan T. Does religious activity improve health outcomes? A critical review of the recent literature. Explore (NY). 2005; 1: 186-191.

17. Asadzandi M. Nursing concepts and theories. Tehran: Center for Compilation of textbooks for the Education and Culture Guard Corps. 2007.

18. Asadzandi M. Critique of Nursing Models at the Level of Applied Concepts and Equations and Model Designing [PhD thesis]. Faculty of Health, Baqiyatallah University of Medical Sciences, Iran. 2001.

19. Asadzandi M. Sound Heart, Spiritual Health from the viewpoint of Abrahamic religions. Journal of Nursing Education \& Palliative Science. Impress. 2018.

20. Asadzandi M. Sound Heart: Spiritual Nursing Care Model from Religious Viewpoint. J Relig Health. 2017; 56: 2063-2075. Ref.: https://tinyurl.com/yyqzhcy6

21. Asadzandi M, Eskandari A, Khademolhosseini SK, Ebadi A. Designing and validation religious evidence-based guidelines of Sound Heart pastoral care model for hospitalized patients. J Med Sci. 2018; 1: 1-9. Ref.: https://goo.gl/Cj7xRz

22. Asadzandi M. Spiritual self-care. Tehran; Resaneh-takhassosi publication. Iran. 2016

23. Asadi M, Asadzandi M, Ebadi A. Effects of spiritual care based on Galba Salim nursing model in reducing anxiety of patients undergoing CABG surgery. Iran J Critical Care Nursing. 2014; 6: 142-151. Ref.: https://goo.gl/FjRwnF

24. Saeidi-Taheri Z, Asadzandi M, Ebadi A. The effect of spiritual care based on Galba Salim model on the sleep quality of the patients with coronary artery disease. Iran J Critical Care Nursing. 2014; 7: 94-103. Ref.: https://goo.gl/njALcz

25. Asadi M, Asadzandi M, Ebadi A. The effect of spiritual care based on Galba Salim model on spiritual experiences of patients undergoing coronary artery bypass surgery. Journal of Cardiology. 2014; 2: 67-73. Ref.: https://goo.gl/7NqUrr

26. SaeidiTaheri Z, Asadzandi M, Ebadi A. The effect of spiritual care based on Galba Salim model on spiritual experience in patients with coronary artery disease. Iranian Journal of Journal of Psychiatric Nursing. 2013; 1: 23-34. Ref.: https://goo.gl/2AUDdc

27. Akbarpour Mazandarani H, Asadzandi M, Saffari M, Khaghanizadeh M. Effect of Spiritual Care Based on Sound-Heart Consulting Model (SHCM) on Spiritual Health of Hemodialysis Patients. Iran J Critical Care Nursing. 2017 10: 1-6. Ref.: https://goo.gl/S1Fs2s 
28. Mazandarani HK, Asadzandi M, Saffari M, Khaghanizadeh M. The Effect of Spiritual Care Based on Sound Heart Model on Quality of Life in Hemodialysis Patients. J Psychiatry Behav Health Forecast. 2018; 1: 1-6.

29. Farsi Z, Asadzandi M, Najafi S. Application of Health Belief Model in Change of Self Care Behaviors of Diabetic Patients. Iran Journal of Nursing. 2010; 22: 61-72. Ref.: https://goo.gl/qXoQCU

30. Asadzandi M, Sekarifard M, Ebadi A, Morovvati Sharif Abad MA, Salari M. Effects of anger management training based on Health Promotion Model on soldiers engage in risky behavior. Iranian Journal of Psychiatric Nursing. 2015; 2: 68- 79. Ref.: https://goo.gl/iWyF22

31. Sayari R, Asadzandi M, SanayiNasab H, Ebadi A. Mental health status of military nurses. Journal of Military Medicine. 2009; 11: 135-141. Ref.: https://goo.gl/TYuaE5

32. Asadizandi M, Saayari R, Sanayi Nasab H, Ebadi A. The Influence of Islamic Ritual Training on Primary Sleep Disorders among Nurses. J Psychiatry Behav Health Forecast. 2018; 1: 1-4. Ref.: https://goo.gl/WpTmWh

33. Asadzandi M. Spiritual counseling. Tehran; Resaneh-takhassosi publication. Iran. 2016.

34. Asadzandi M. Spiritual Empowerment Program Based on Sound Heart Model in the Cancerous Children's Family. Annals of Nursing Research and Practice. 2018; 3: 10-26. Ref.: https://goo.gl/6Xyiiy

35. Asadzandi M, Vafadar Z. Designing Inter Professional Spiritual Health Care Education Program for Students of Health Sciences. Journal of Nursing and Patient Health Care. 2018; 1: 1-6. Ref.: https://goo.gl/NgaxoM

36. Streubert C. Qualitative research in nursing (advancing the humanistic imperative). Philadelphia: Lippincott com. 1990.

37. Dastgheib SA. Great sins. Qom: Dar al-Ketab Publications. 2016.

38. Dastgheib SA. Sound Heart. Qom: Dar al-Ketab Publications. 2018.

39. Pourm Y, Rezaei M, Borhani M, Bakhtiari A. Review Quranic verses in the context of three major dimensions of health. The Journal of Islam and Islam. 2015; 2: 23-36.

40. Asadzandi M. Treatment touch from the viewpoint of positivism and Islam. Nursing and Midwifery Faculty Quarterly of Shahid Beheshti. 2004=5; 2: 72-83.

41. Dastgheib SA. Resurrection. Qom: Dar al-Ketab Publications. 2016.

42. Pourm, Rezaei M., Borhani M, Bakhtiari A. Review Quranic verses in the context of three major dimensions of health. The Journal of Islam and Islam. 2015; 2: 23-36.

43. Mohammadi Rey Shahri M. Encyclopedia of the Holy Quran. Translator: Hamid Reza Sheikhi. Qom, Dar al-Hadith, first print, Taha. 2016.

44. Asadzandi M. The role of spiritual health in the diagnosis and treatment of diseases. Internal Journal of the Islamic Republic of Iran Medical Academy. 2016; Ref.: https://goo.gl/thfbU7

45. Abolghasemi $\mathrm{H}$, Asadzandi $\mathrm{M}$. Reinforcing faith, the main care and method of maintaining and improving the spiritual health of patients and clients. Journal of Health Promotion. Islamic Republic of Iran Medical Academy. 2017;1: 39-49.

46. Asadzandi M. Dream theory from the perspective of Islam. International Journal of Psychotherapy Practice and Research. 2018; 1: 1-7. Ref.: https://goo.gl/TJPHtX

47. Asadzandi M. Professors, spiritual characteristics for role- modeling education. Education strategies in Medical Sciences Journal. 2017; 10: 23-35. Ref.: https://goo.gl/8MNb2Z

48. Tabatabaee M. Tfsyr Al-Mizan (Sayed Mohammad Mvsvyhmdany, Trans.). Qom: Office of Publications. 1971; Ref.: https://goo.gl/LNjJoo

49. Gheraati M. Noor interpretations. 12: (2nd edition.). Tehran: Cultural Center of Quran. 2006.

50. Shirazi M, Sample Commentary. Tehran. Publications: Islamic library. 2017. 2018.

51. Motahari M. The Prophet's lifestyle. Qom: Islamic Publications office. 1983a.

52. Motahari M. The evolution of human social. Qom: Sadra Publications. 1975.

53. Motahari M. Human and faith. Qom: Sadra Publications. 1986.

54. Asadzandi M, Ebadi A. Designing and determining psychometric properties of an inventory for analysis of patients' spiritual responses to diseases. Baqiyatallah University of Medical Sciences, Tehran. 2013. 